\title{
Matrigel uses in cell biology and for the identification of thymosin $\beta 4$, a mediator of tissue regeneration
}

\author{
Hynda K. Kleinman ${ }^{1} \cdot{\text { Kyeongsoon } \mathrm{Kim}^{2,3} \cdot \text { Hunhee Kang }}^{3}$
}

Received: 11 September 2018/Accepted: 18 September 2018/Published online: 26 September 2018

(C) The Korean Society for Applied Biological Chemistry 2018

\begin{abstract}
The thin extracellular matrix that is found basally in epithelial and endothelial cells and around smooth muscle, peripheral nerves, and fat cells is known as the basement membrane. A murine tumor matrix extract, termed Matrigel, has provided an abundant source of basement membrane proteins (laminin, collagen IV, heparan sulfate, etc.). Matrigel gels at room temperature into a structure similar to the authentic matrix. Embryonic tissue explants, stem cells, and various cell types differentiate when cultured on Matrigel. Matrigel has been used in various in vitro assays for angiogenesis, cell invasion, spheroid formation, organoid formation from a single cell, etc. In vivo Matrigel improves/promotes tumor xenograft growth and is used to measure angiogenesis, improve heart and spinal cord repair, increase tissue transplant take, etc. Endothelial cells plated on top of Matrigel form capillarylike tubules. The gene for thymosin beta 4 was induced at $4 \mathrm{~h}$ after plating endothelial cells on Matrigel, and when the thymosin beta 4 protein was added exogenously to the culture, tubule formation was accelerated. Thymosin beta 4 , a small $43 \mathrm{kDa}$ protein present in all body fluids and cells, has multiple biological activities, including reducing inflammation, apoptosis, and cytotoxicity while increasing cell migration, stem cell recruitment and differentiation, and tissue repair. Thymosin beta 4 was subsequently found to promote angiogenesis in vivo and to improve dermal and
\end{abstract}

Hynda K. Kleinman

hyndakk@gmail.com

1 The George Washington University School of Medicine, Washington, DC, USA

2 Department of Pharmaceutical Engineering, Inje University, Kimhae 50834, Republic of Korea

3 GtreeBNT Co., Ltd., Seongnam-si 13554, Republic of Korea ocular healing in experimental injury models. It has regenerative activity in animal models of traumatic brain injury, stroke, multiple sclerosis, heart attack, peripheral neuropathy, liver and kidney fibrosis, and hair growth. Clinical trials have demonstrated its efficacy for both stasis and pressure ulcers and for both dry eye and a rare ocular disease. This mini review will discuss the development of Matrigel and the discovery of thymosin beta 4 as a regenerative protein that is upregulated when endothelial cells are plated on Matrigel.

Keywords Matrigel $\cdot$ Thymosin beta 4 - Organoids $\cdot 3 \mathrm{D}$ culture $\cdot$ Tissue regeneration

\section{Introduction}

The extracellular matrix (ECM) forms outside of the cells and serves as a "glue" to hold cells together in tissues. Various types of ECM have been identified that are tissuespecific. These matrices are generally composed to collagens, proteoglycans, and glycoproteins. The basement membrane matrix is a specialized ECM found in contact with epithelial, endothelial, smooth muscle, peripheral nerve, and fat cells. It is primarily composed of collagen IV, heparan sulfate proteoglycan, laminins, and various growth factors [1]. In an attempt to characterize the interactions of these components, a crude guanidine extract was made from a murine tumor rich in basement and this extract was found to gel into structures similar to the native basement membrane matrix at the electron microscopy level [2]. Three-dimensional (3D) culture of cells and explants on this gelled basement membrane matrix (Matrigel) has defined the role of the basement membrane in 
(A)

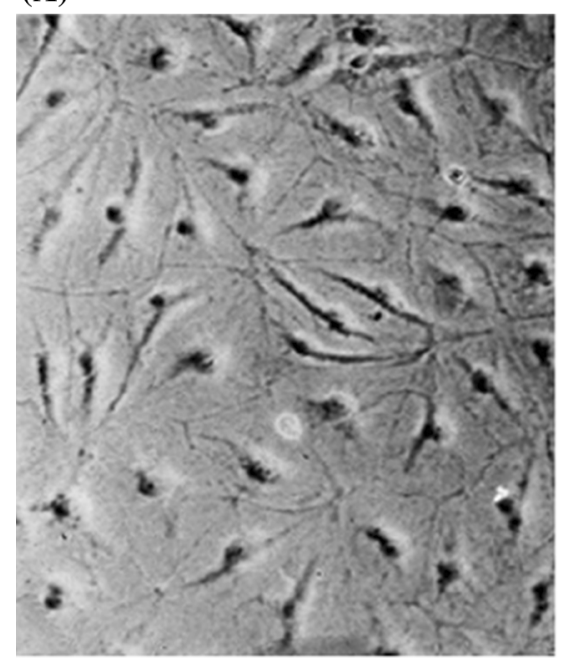

(B)

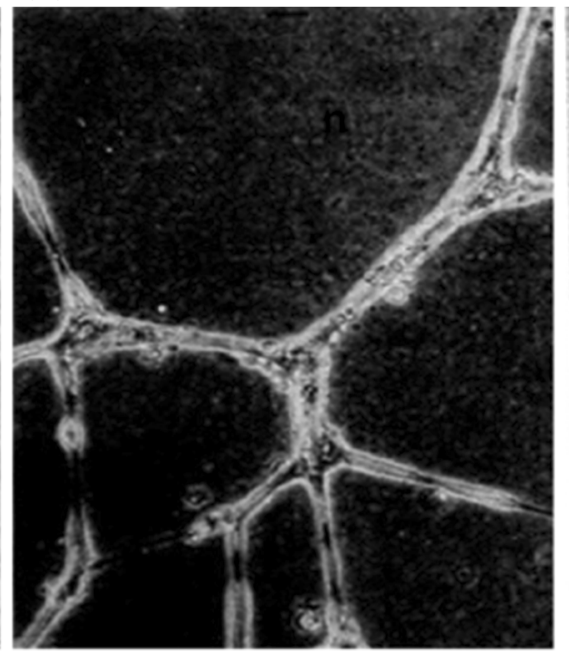

(C)

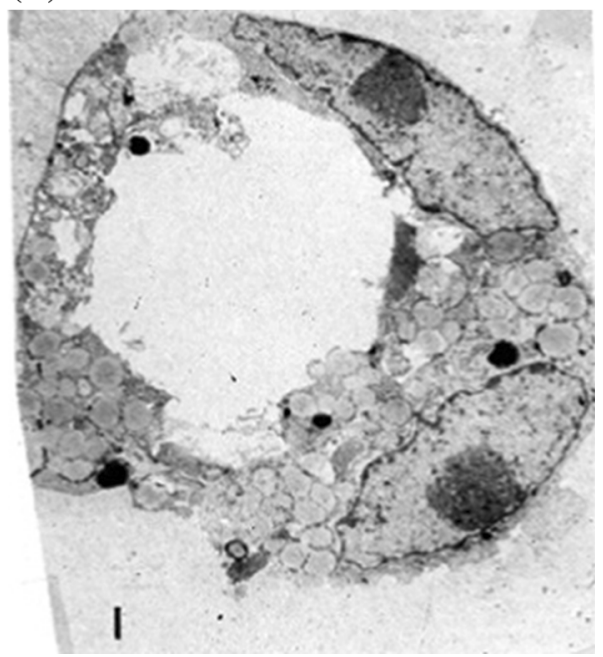

Fig. 1 Endothelial cells on collagen (A), Matrigel (B), and Matrigel in cross section (C). Panels are from [5]

tissue development, maintenance, and disease [3-6] (Fig. 1).

\section{Matrigel promotes cell differentiation and explant outgrowth/differentiation}

On tissue culture plastic, most cells rapidly grow in monolayer. Type I collagen coatings and gels have been found to promote the differentiation of some cells, such as muscle and hepatocytes [7, 8]. On Matrigel, the differentiation of these cells and many others is more advanced. On Matrigel, non-malignant cells do not grow but rather differentiate into their respective phenotypes [6]. For example, salivary gland cells form acini, cardiomyocytes aggregate and begin beating, breast epithelial cells form spherical structures and secrete milk into their lumen, etc. [6, 9-11]. Explants also differentiate with aortic rings sprouting blood vessels, spinal ganglia explants have neurite outgrowth with Schwann cells producing myelin, salivary gland rudiments form ducts and acini, etc. [12-14].

\section{Assay development with Matrigel}

Since many different cell types differentiate when grown in or plated on Matrigel in vitro, various assays using Matrigel have been developed (Table 1). In suspension culture with Matrigel, tumor cells grow and form spheroid structures that have been used to test different therapeutic agents as well as genes important in malignancy [3, 11]. Furthermore, when these spheroids are subsequently plated on Matrigel, the invasive nature of the cells can be determined by the sprouting/invasive behavior of the cells [1]. A dormancy assay has also been developed as dormant cells will not grow on Matrigel but will grow on tissue culture plastic [15]. This lack of a growth response on Matrigel can be used to identify and even isolate dormant cells. The factors that maintain cells in a dormant state and those that trigger emergence have been studied in this model. Metastatic tumor cells generally cross a basement membrane matrix during invasion into tissues and into the blood stream. An assay using Matrigel as a barrier has provided a quantitative, reliable, and quick method for testing the invasive nature of cells, and for determining factors that either inhibit or promote invasion [16]. This Matrigel invasion assay has been in use for more than 30 years and can also be used to select for highly malignant or low malignant cells as well as identify genes important in invasion [17]. Many of these in vitro assays with tumor cells are performed under hypoxic conditions in low glucose to mimic the in vivo tumor microenvironment, and the findings differ in some cases from that found with normoxia. The relationship between different cells in the tumor microenvironment can also be identified using these in vitro assays in co-culture or tri-culture [1, 18]. Matrigel also promotes the take and growth of tumor cells and tumor biopsy specimens allowing for animal models to study therapeutics [19, 20].

Non-malignant cells and tissue explants plated on Matrigel have also been used as assays for development. For example, aortic rings when plated on Matrigel develop sprouts of blood vessels in a simple ex vivo assay that can be used to define various promoters or inhibitors of angiogenesis [12]. Highly selected single stem cells have been found to grow and differentiate into organoids when plated on Matrigel [21]. Such recapitulation of development allows for studying genes important in normal 
Table 1 Examples of basic in vitro and in vivo assays using Matrigel

\begin{tabular}{|c|c|}
\hline Assay & Main uses \\
\hline \multicolumn{2}{|l|}{ In vitro assays } \\
\hline Invasion assay & Identify invasive cells, select for invasive cells, test therapeutics, identify genes important in invasion \\
\hline $\begin{array}{l}\text { Tumor } \\
\text { spheroid }\end{array}$ & Provides models for testing therapeutics and identifying genes affecting tumor growth \\
\hline $\begin{array}{l}\text { Dormancy } \\
\text { assay }\end{array}$ & Determine dormant state of cells and factors regulating dormancy \\
\hline Tube assay & Endothelial cells on Matrigel to quantitative factors/genes important in angiogenesis and to identify endothelial precursor cells \\
\hline Organoid & Study development, test factors regulating development, stem cell differentiation \\
\hline $\begin{array}{l}\text { Aortic ring } \\
\text { In vivo assays }\end{array}$ & Test factors and genes regulating angiogenesis (ex vivo assay) \\
\hline Xenograft & $\begin{array}{l}\text { Cell and patient-derived xenografts, increased take and growth, allows for models of human cancers to be studied for } \\
\text { therapeutics in rodents }\end{array}$ \\
\hline Plug & Subcutaneous Matrigel for testing angiogenic and anti-angiogenic factors \\
\hline DIVVA & Angiogenesis assay inside a plastic tube \\
\hline
\end{tabular}

development as well as providing potential replacement tissue for in vivo implantation. Endothelial cells on Matrigel form tubules [5, 22, 23]. This quick, quantitative, reliable, and easy assay has been used for more than 40 years. The "tube assay" has been used to define angiogenic and anti-angiogenic factors and genes important in angiogenesis. It has also been used to study tumor cell migration along vessel structures [24, 25]. This assay has been used to identify a gene, thymosin beta 4 , important in tissue repair and regeneration [26].

\section{Identification of thymosin beta 4 , a gene upregulated during endothelial tube formation on Matrigel: animal studies}

Thymosin beta 4 was identified as a gene upregulated at $4 \mathrm{~h}$ after endothelial cells were plated on Matrigel [26]. It contains 43 amino acids, is found in both body fluids and cells, and has multiple biological activities (Table 2) with cells in vitro and in animal models of tissue injury and disease in vivo $[27,28]$. Thymosin beta 4 is a regenerative, multifunctional protein. Besides promoting tube formation in vitro as demonstrated by exogenous addition, gene overexpression, and SiRNA, thymosin beta 4 also promoted angiogenesis in vivo in various assays, including the Matrigel plug assay. It was then shown to promote dermal healing in normal mice and rats, steroid-treated rats (impaired healing model), diabetic mice, and aged mice [29]. Thymosin beta 4 reduced the level of myofibroblasts and allowed for better organization of the collagen I fibers [30]. It also promoted the healing of dermal rodent burns and promoted skin flap attachment [31, 32]. These studies provided the scientific rationale for testing in human dermal injuries as described below.

Thymosin beta 4 also promoted ocular healing in various rodent injury models $[33,34]$. It inhibited inflammation by various mechanisms, including reducing inflammatory mediators, decreasing neutrophil infiltration, and decreasing NF-KappaB activation. Laminin-332, a molecule

Table 2 Biological activities of thymosin beta 4

\footnotetext{
Migration: increased keratinocytes, corneal epithelial cells, stem cells, etc., decreased neutrophil migration

Gene expression: increased VEGF, angiopoietin, laminin-332, zyxin, etc., decreased inflammatory mediators

Angiogenesis: increased endothelial precursor recruitment and migration, increased angiogenic factors

Cytoprotection: decreased oxidative stress, AGEs, ROS

Anti-apoptosis: many genes involved in apoptosis are regulated by thymosin beta 4

Anti-inflammation: decreased Nf-KappaB, inflammatory mediators, neutrophil infiltration, etc.

Anti-fibrotic: decreased myofibroblasts

Antimicrobial

Stem cell differentiation: tissue regeneration
} 
important in cell migration and cell-cell and cell-matrix interactions, was increased by thymosin beta 4 . It is important to note that no increase in blood vessel formation was observed in the eye. Additionally, in a rodent model of dry eye, thymosin beta 4 increased the number of goblet cells, mucin production, corneal integrity, and tears and decreased 17 inflammatory mediators and the wound area [35]. These studies demonstrate not only the rationale for using thymosin beta 4 in a clinical trial of dry eye but also demonstrate some of the repair mechanisms involved.

Various additional animal studies found that systemically injected thymosin beta 4 healed and regenerated injured tissue in the heart (ligation ischemia and reperfusion injury), lung (fibrosis), brain (traumatic brain injury, multiple sclerosis, and stroke), peripheral nerves (neuropathy), kidney (fibrosis), liver (fibrosis), etc. In some cases (cardiac repair), only one injection was required, while multiple injections given every 3 days were needed for other organs [27, 28]. Similar mechanisms involving reduced inflammation and apoptosis, cytoprotection, angiogenesis, stem cell recruitment, and cell migration were important in the tissue repair/regeneration observed in these studies.

Table 3 Clinical trials with thymosin beta 4

\begin{tabular}{llr}
\hline Phase & Study & Number of patients \\
\hline \multicolumn{2}{l}{ Completed trials } & \\
1 & Dermal topical gel: safety study & 15 \\
1 & Intravenous: safety study & 60 \\
2 & Venous stasis ulcers: topical gel & 72 \\
2 & Pressure ulcers: topical gel & 71 \\
2 & Epidermolysis bullosa: topical gel & 30 \\
2 & Neurotrophic keratitis: eye drops & 9 \\
2 & Severe dry eye: eye drops & 9 \\
2 & Moderate to severe dry eye: eye drops & 72 \\
$2 \mathrm{~b} / 3$ & Moderate to severe dry eye: eye drops & 317 \\
3 & Moderate to severe dry eye: eye drops & 600 \\
Ongoing trial & \\
3 & Neurotrophic keratitis: eye drops & 46 \\
Planned trials & \\
2 & Epidermolysis bullosa: dermal gel & 15 \\
3 & Epidermolysis bullosa: dermal gel & 150 \\
3 & Moderate to severe dry eye: eye drops & 700 \\
\hline
\end{tabular}

Outcomes all demonstrated safety and tolerability as well as efficacy trends and, in many cases, significant efficacy

\section{Thymosin beta 4 clinical trials}

Over 1200 patients have been involved in clinical trials with thymosin beta 4 (Table 3) [36 and unpublished]. Safety studies with a topical dermal gel and an injectable formulation have not identified any safety issues. This finding is consistent with all of the toxicology and safety studies done preclinically in animals. Thymosin beta 4 was tested in three dermal phase 2 trials for venous stasis ulcers (poor leg circulation), pressure ulcers (bed sores), and epidermolysis bullosa (a gene disease involving skin blistering). In all cases, there were no safety issues, and there was a trend toward better and faster healing in the treated groups than that in the placebo group. Additional clinical trials for epidermolysis bullosa are planned for the near future.

Thymosin beta 4 has shown efficacy for healing the eye in 4 ocular trials for severe dry eye (phase 2) and for moderate to severe dry eye (phases $2,2 \mathrm{~b} / 3$, and 3 ) (Table 3) [37, 38, and unpublished]. It promoted the healing of the injured ocular surface and improved the comfort of the patients. No safety issues were found, and the treatment had a drop comfort similar to artificial tears. Another trial (phase 3) is planned to obtain drug approval. A phase 3 trial for a rare ocular disease, neurotrophic keratitis, is ongoing.

\section{Summary and future directions}

Matrigel has unexpected wide uses (over 11,000 citations in PubMed) for studying cell differentiation and cancer cell behavior. Cells and explants plated on Matrigel have the tissue-specific expected in vivo morphology and gene expression. Mechanisms of these processes can now be probed and identified in vitro. Matrigel has allowed for various models and assays for identifying factors and genes that affect these processes [1]. One regulatory gene, thymosin beta 4 , identified using the endothelial cell tube formation assay was found to have many reparative and regenerative activities [27, 28]. Clinical trials demonstrated its safety and efficacy in patients with dermal and ocular injuries [29].

Preliminary studies with Matrigel on in vivo repair in animal models predict that once a human equivalent is prepared, it may have use for tissue repair (such as spinal cord and heart injury), tissue/organoid transplantation, tissue scaffolds, stem cell transplantation, etc. [39]. Mixed scaffolds of alginate: Matrigel have already shown promise for tissue engineering and it is likely that other combinations with Matrigel will be developed. It is also anticipated that new assays will be developed and existing assays will 
have additional uses. The recent use of neurospheres grown in Matrigel for testing Zika virus inhibition of brain cell growth is an example of the potential of the present and future assays using Matrigel [40].

Clinical trials with thymosin beta in the eye and skin showed its safety, tolerability, and efficacy. There are considerable other tissue injuries (brain, spinal cord, heart, liver, lung, etc.) with extensive preclinical efficacy shown in animal models. Such studies suggest that thymosin beta 4 may have additional uses in the clinic for various injuries $[27,28]$. There is a lot of excitement now on the regenerative properties of stem cells, but most studies show that the cells themselves do not remain in the tissue and replace the damaged cells but rather secrete factors that recruit endogenous tissue stem cells. Thymosin beta 4 is likely one of those important secreted regenerative factors. Studies in heart damage have shown that stem cells with silenced thymosin beta 4 are ineffective in repairing heart damage, while control stem cells can repair heart damage [41]. Further studies are needed, but it is possible that risky and costly stem cell transplants may be replaced with injected thymosin beta 4 .

Acknowledgments The early studies on Matrigel and some of the preclinical work on thymosin beta 4 were performed by HKK and were carried out at the National Institutes of Health (NIH) with support from NIH, Bethesda, MD, USA. The authors thank the members of GTreeBNT for providing information on their planned clinical trials.

\section{Compliance with ethical standards}

Conflict of interest Hynda K. Kleinman, and Kyeongsoon Kim consult for GtreeBNT. Hunhee Kang is an employee of GtreeBNT.

\section{References}

1. Benton G, Arnaoutova I, George J, Kleinman HK, Koblinski J (2016) Matrigel: from discovery and ECM mimicry to assays and models for cancer research. Adv Drug Discov Rev 79-80:3-18

2. Kleinman HK, McGarvey ML, Hassell JR, Star VL, Cannon FB, Laurie GW, Martin GR (1986) Basement membrane complexes with biological activity. Biochemistry 25:312-318

3. Benton G, Kleinman HK, George J, Arnaoutova I (2012) Multiple uses of basement membrane-like matrix (BME/Matrigel) in vitro and in vivo with tumor cells. Int J Cancer 128:1751-1757

4. Arnaoutova I, George J, Kleinman HK, Benton G (2012) Basement membrane (BME) has multiple uses with stem cells. Stem Cell Rep Rev 8:163-169

5. Kubota Y, Kleinman HK, Martin GR, Lawley TJ (1988) Role of laminin and basement membrane in the differentiation of human endothelial cells into capillary-like structures. J Cell Biol 107:1589-1597

6. Benton G, George J, Kleinman HK, Arnaoutova (2009) Advancing science and technology via $3 \mathrm{D}$ culture on basement membrane matrix. J Cell Physiol 221:18-25

7. Themistoceous GS, Katapodois H, Sourla A, Lembessis P, Doillon CJ, Soucacos PN, Koutsilieris M (2004) Three- dimensional type I collagen cell culture systems for the study of bone pathophysiology. In Vivo 18:687-696

8. Kleinman HK, Klebe RJ, Martin GR (1981) Role of collagenous matrices in the adhesion and growth of cell. J Cell Biol $88: 473-485$

9. Hoffman MO, Kibbey MC, Letterio JJ, Kleinman HK (1996) Role of laminin-1 and TGF-beta 3 in acinar differentiation of a human submandibular gland cell line (HSG). J Cell Sci 109:2013-2021

10. Pasquier J, Gupta R, Bioult D, Hoarau-Vechot J, Courjaret R, Machaca K, Al Suwaidi J, Stanley EG, Fafii EG, Da Elliott, Abi Khalil C, Rafii A (2017) Coculturing with endothelial cells promotes in vitro maturation and electrical coupling of human embryonic stem cell-derive cardiomyocytes. J Heart Lung Transplant 36:684-693

11. Bissell MJ, Ran TG (1999) Regulation of functional cytodifferentiation and histogenesis in mammary epithelial cells: role of the extracellular matrix. Environ Health Perspect 80:61-70

12. Gho YS, Kleinman HK, Sosne G (1999) Angiogenic activity of human soluble intercellular adhesion molecule-1. Cancer Res 59:5128-5132

13. Carey DJ, Todd MS, Rafferty CM (1986) Schwann cell myelination: induction by exogenous basement membrane-like extracellular matrix. J Cell Biol 102:2254-2263

14. Hauser BR, Hoffman MP (2015) Regulatory mechanisms driving salivary gland organogenesis. Curr Top Dev Biol 115:111-130

15. Barkan D, Kleinman HK, Simmons JL, Asmussen H, Kamaraju AK, Hoenorhoff M, Liu Z, Coste SV, Cho EH, Lockett SJ, Khanna C, Chambers AF, Green J (2008) Transition from tumor dormancy to metastatic growth is dependent on the extracellular matrix and cytoskeletal dynamics. Can Res 68:6241-6250

16. Albini A, Iwamoto Y, Kleinman HK, Martin GR, Kozlowski JM, McEwan RN (1987) A rapid in vitro assay for quantitating the invasive potential of tumor cells. Cancer Res 47:3239-3245

17. Albini A, Noonan DM (2010) The 'chemoinvasion' assay, 25 years and still going strong: the use of reconstituted basement membranes to study cell invasion and angiogenesis. Curr Opin Cell Biol 22:677-689

18. Benton G, DeGray G, Kleinman HK, George J, Arnaoutova I (2015) In vitro microtumors provide a physiological predictive tool for breast cancer therapeutic screening. Plos One 10(4):e0123312

19. Fridman R, Kibbey MC, Royce LS, Zain M, Sweeney TM, Jicha DL, Yannelli JR, Martin GR, Kleinman HK (1991) Basement membrane (matrigel) enhances both the incidence and growth of subcutaneously injected human and murine cells. J Natl Cancer Inst 83:769-774

20. Fridman R, Benton G, Arnaoutova I, Kleinman HK, Bonfil D (2012) Increased initiation and growth of tumor cell lines, cancer stem cells, and biopsy material in mice using basement membrane proteins (Cultrex/Matrigel) coinjection. Nat Protoc 17:1138-1144

21. Cristobal A, van der Toorm HW, van der Wetering M, Clevers H, Heck A, Mohammed S (2107) Personalized proteome profiles of healthy and tumor colon organoids reveal both individual diversity and basic features of colorectal cancer. Cell Rep 18:263-274

22. Arnaoutova I, Kleinman HK (2010) In vitro angiogenesis: endothelial cell tube formation on a gelled basement membrane extract. Nat Protoc 5:628-635

23. Arnaoutova I, George J, Kleinman HK, Benton G (2009) The endothelial cell tube formation assay on basement membrane turns 20. Angiogenesis 12:267-274

24. Lugassy C, Wadehra M, Li X, Corselli M, Akhavan D, Binder SW, Péault B, Cochran AJ, Mischel PS, Kleinman HK, Barnhill RL (2013) Pilot study on "pericytic mimicry" and potential embryonic/stem cell properties of angiotropic melanoma cells 
interacting with the abluminal vascular surface. Cancer Microenviron 6:19-29

25. Zadran S, McMickle R, Shackelford D, Kleinman H, Barnhill R, Lugassy C (2013) Monitoring extra-vascular migratory metastasis (EVMM) of migrating cancer cells using an in vitro co-culture system. Protoc Exch 2013:2867

26. Grant DS, Kinsella JL, Kibbey MC, LaFlamme S, Burbelo PD, Goldstein AL, Kleinman HK (1995) Matrigel induces thymosin beta4 gene in differentiating endothelial cells. J Cell Sci 108:3685-3694

27. Goldstein AL, Hannappel E, Kleinman HK (2005) Thymosin $\beta 4$ : actin-sequestering protein moonlights to repair injured tissues. Trends Mol Med 11:421-429 (invited)

28. Goldstein A, Kleinman HK (2015) Advances in the basic and clinical applications of thymosin beta 4. Expert Opin Biol Ther 15(Suppl 1):S139-S145. https://doi.org/10.1517/14712598.2015. 1011617

29. Kleinman HK, Sosne G (2016) Thymosin beta 4 promotes dermal healing. Vit Hormone 102:251-275

30. Ehrlich HP, Hazard SW 3rd (2010) Thymosin beta 4 enhance repair by organizing connective tissue and preventing the appearance of myofibroblasts. Ann NY Acad Sci 1194:118-124

31. Kim S, Kwon J (2017) Thymosin beta 4 has a major role in dermal burn wound healing that involves actin cytoskeletal remodeling. J Tissue Eng Regen Med 11:1262-1273

32. Lin Y, Lin B, Lin D, Huang G, Cao B (2015) Effect of thymosin beta 4 on the survival of random skin flaps in rats. J Reconstr Microsurg 31:464-470

33. Sosne G, Chan CC, Thai K, Kennedy M, Szliter EA, Hazlett LD, Kleinman HK (2001) Thymosin beta 4 promotes corneal wound healing and modulates inflammatory mediators in vivo. Exp Eye Res 72:605-608
34. Sosne G, Szliter EA, Barrett R, Kernacki KA, Kleinman HK, Hazlett LD (2002) Thymosin beta 4 promotes corneal wound healing and decreases inflammation in vivo following alkali injury. Exp Eye Res 74:293-299

35. Kim CE, Kleinman HK, Sosne G, Ousler GW, Kim K, Kang S, Yang J (2018) RGN-259 (thymosin beta 4) promotes clinically important dry eye efficacies in comparison with prescription drugs in a dry eye model. Sci Rep 8(1):10500. https://doi.org/10. 1038/s41598-018-28861-5

36. Treadwell T, Kleinman HK, Crockford D, Hardy MA, Guarnera $\mathrm{T}$, Goldstein A (2012) The regenerative peptide thymosin beta 4 accelerates the rate of healing of pressure and venous stasis ulcers: analysis of two phase 2 randomized clinical trials. NY Acad Sci 1270:37-44

37. Sosne G, Dunn SP, Kim C (2015) Thymosin beta 4 significantly improves the signs and symptoms of severe dry eye in a phase 2 randomized trial. Cornea 34:491-496

38. Dunn SP, Heidemann DG, Chow CY, Crockford D, Turjman N, Angel J, Allan CB, Sosne G (2010) Treatment of chronic nonhealing neurotrophic corneal epithelial defects with thymosin beta 4. Arch Ophthalmol 128:636-638

39. Kleinman HK, Martin GR (2005) Matrigel: basement membrane matrix with biological activity. Semin Cancer Biol 15:378-386

40. Garcez PP, Loiola EC, Madeiro da Costa R, Higa LM, Trindade P, Delvecchio R, Nascimento JM, Brindeiro R, Tanuri A, Rehen SK (2016) Zika virus impairs growth in human neurospheres and brain organoids. Science 352(6287):816-818

41. Hinkel R, El-Aouni C, Olson T, Horstkotte J, Mayer S, Müller S, Willhauck M, Spitzweg C, Gildehaus FJ, Münzing W, Hannappel E, Bock-Marquette I, DiMaio JM, Hatzopoulos AK, Boekstegers $\mathrm{P}$, Kupatt C (2008) Thymosin beta 4 is an essential paracrine factor of embryonic endothelial progenitor cell-mediated cardioprotection. Circulation 117:2232-2240 